\title{
Reduction of Wave Energy Due to Monotypic Coastal Vegetation Using Response Surface Methodology (RSM)
}

\author{
S. Hemavathi $\uparrow$ and R. Manjula \\ Department of Civil Engineering, National Institute of Technology, Tiruchirappalli, Tamil Nadu, India \\ †Corresponding author: S. Hemavathi; hema160504@gmail.com
}

\section{Nat. Env. \& Poll. Tech. \\ Website: www.neptjournal.com \\ Received: 08-04-2020 \\ Revised: 02-06-2020 \\ Accepted: 03-06-2020 \\ Key Words: \\ Flume experimentation \\ Aquatic vegetation \\ Cymodocea serrulata \\ Seagrass meadow \\ Response surface \\ methodology}

\begin{abstract}
Information of interactions between waves and aquatic vegetation is becoming increasingly important, in particular, due to the trend of plant-induced wave attenuation towards sustainable coastal management systems. This study aims to understand monotypic vegetation-wave interactions through three-level, four factors, response surface methodology (RSM) using laboratory wave flume under controlled conditions. Cymodocea Serrulata is one of the prevalent monotypic seagrass species found in the Gulf of Mannar, Tamilnadu, South India. It was physically simulated using synthetic plant imitations to create a relationship between wave attenuation $(E \%)$ and four direct control factors, i.e., water depth $(h)$, wave period $(T)$, plant density $(N)$ and bed roughness factor $(f)$ using an empiric model. The model developed was tested using the analysis of variance technique (ANOVA) and evaluated for the main and interaction effects of the studied parameters. The findings showed that both individually and in combination, all of the parameters considered were significantly effective on $E \%$. All modelbased findings were compared with a new collection of experimental data and validation tests were performed. The comparison of experimental results with model predictions was at a good agreement with a high coefficient of determination $\left(R^{2}\right)$ of 0.98 (with $p$-value $<0.05$ ).
\end{abstract}

\section{INTRODUCTION}

The rise in sea level and land subsidence along the heavily populated coastline has been recognized as a major threat to coastal regions in many countries around the world. Natural coastal habitats, such as seagrasses, salt marshes and mangrove forests, provide a wide range of ecological services (Larkum et al. 2006, Manca et al. 2012, Specht et al. 2015, $\mathrm{Xu}$ et al. 2017) and serve as foreshore vegetation structures (Guannel et al. 2015, Vuik et al. 2018). Such structures potentially mitigate the intensity of tides and waves at locations where they are situated in front of flood control structures. It is well known that vegetated foreshore structures affect local hydrodynamic climate (Koch et al. 2006). The interface of the ocean with dry land reduce wave heights, create mixing layers (Luhar \& Nepf 2016) and regulate turbulence due to waves that break in shallow water and attenuate vegetation waves. This natural occurrence has led to the concept of sustainable coastal conservation and protection through the use of natural seagrass wetlands, salt marshes and the mangrove forest network. With a growing population and infrastructure alongside low-lying coastal areas, the potential of coastal vegetation to serve as a bio-shield or non-intrusive buffer to mitigate the combined effects of rising sea levels has recently increased interest (Feagin et al. 2019). In this research, an empirical model based on an experimental design for the transformation of waves over monotypic underwater vegetation (Cymodocea Serrulata species) is constructed within a laboratory flume. A three-level, four-factor, Central Composite Response Surface Methodology (RSM)) was selected for analysis.

\section{THEORETICAL BACKGROUND}

For linear waves, Eqn.1 provides a general formula for measuring wave height when translated into energy density (E)

$$
E=\frac{1}{8} \rho g H^{2}
$$

Where $r$ is seawater density, $g$ is the acceleration of gravity, and $H$ is the height of the wave. The reduction in wave energy density was determined by Fonseca and Cahalan (Fonseca \& Cahalan 1992) using a percentage reduction in energy density $(E \%)$ over a $1 \mathrm{~m}$ test segment:

$$
E \%=\left[\left\{\frac{E(\text { in })-E(\text { out })}{E(\text { in })}\right\} \times 100\right]
$$

Where $E$ (in) is the energy density entering the $1 \mathrm{~m}$ test section, and $E$ (out) the energy density leaving the $1 \mathrm{~m}$ test section. 


\section{MATERIALS AND METHODS}

The experiments were performed in the flume of the fluid mechanics laboratory, National Institute of Technology Tiruchirappalli (NITT), Tamilnadu, India. The wave flume measures $12.5 \mathrm{~m}$ in length, $0.3 \mathrm{~m}$ in width and $0.6 \mathrm{~m}$ in depth and is equipped with an electro-hydraulic piston wave generator on one side of the flume. To stop the wave reflection, a 1:7 aspect ratio rubble masonry wave absorber was mounted in the opposite direction of the wave generator. A monotypic artificial plant meadow of one meter in length was placed in the middle portion of the flume. The meadow starts about $4 \mathrm{~m}$ away from the wave paddle.

Monotypic conditions on the Cymodocea serrulata meadow: Species of Cymodocea serrulata, a coastal seagrass plant with roots, stems and leaves, forming thick vegetative colonies primarily in shallow estuaries (Kuo \& den Hartog 2006). It has a smaller leaf structure with whorl-like blades that distinguish it from other seagrass species. India's seagrasses contain 14 populations of about 50 species from seven genera worldwide (Kuo \& den Hartog 2006). The Gulf of Mannar and Palk Bay are mainly located in southeast coastal regions as well as island lagoons from Lakshadweep to the Andaman Sea and Nicobar in the East of India's Bay of Bengal.

The physical properties of the selected plants are important for studying wave interactions, leaf bends and the resulting efficiency of wave dampings, such as density and rigidity. In the current research, artificial polypropylene models are chosen on the basis the most similar physical characteristics to real leaves such as the elasticity modulus $E=0.9 \mathrm{GPa}$ in the Cymodocee Serrulata meadow (Fig. 1). For a typical natural Serrulata Cymodocea with 4-5 leaves, stems with 1

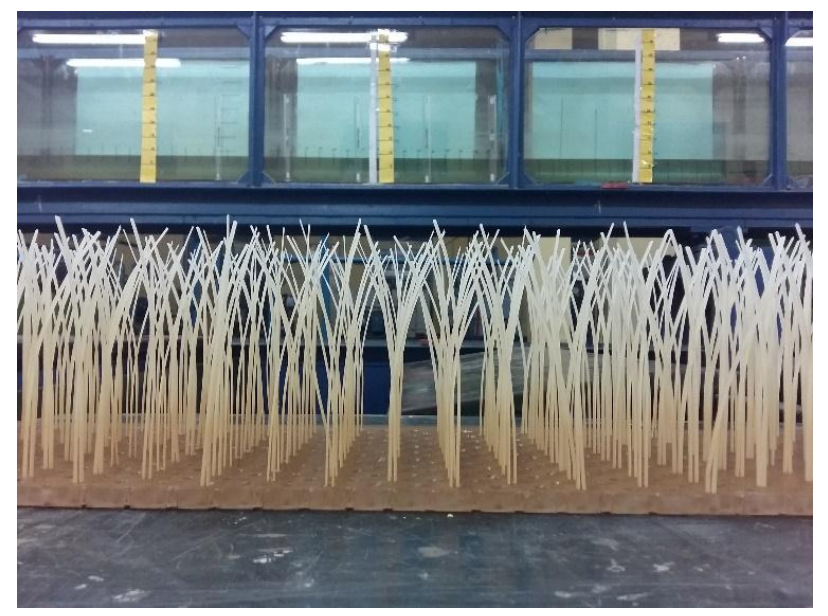

Fig. 1: Morphological features used for the synthetic analysis of plant species. cm (10-20 cm long and 3-5 mm wide), arranged in opposite directions, each with a length of up to $15 \mathrm{~cm}$ can be fitted.

Artificial polypropylene plants of the Cymodocea serrulata have a diameter of $0.15 \mathrm{~m}$ long leaves with polypropylene streaks (Fig. 1 and 2). Each simulated plant has four leaves attached to a stem of $0.01 \mathrm{~m}$. The mimics were mounted on a standard $1 \mathrm{~m}$ and $0.26 \mathrm{~m}$ acrylic base frame and connected to a staggered distribution with a width of 43 $\mathrm{mm}$ to retain the plant density of 543 stems/sqm. Likewise, a spacing of $21.5 \mathrm{~mm}$ was maintained to achieve a plant density of 2163 stems/sqm. Digital HD Video Camera Recorder SONY, Model No: $25 \mathrm{~Hz}$ HDR-PJ50V has captured both the experiment and the wave profiles. The captured video images were processed using the MATLAB image processing method and the time series were obtained for the wave profile. The wave height was used to measure wave attenuation before and after the wave.

\section{CENTRAL COMPOSITE DESIGN (CCD)}

Experimental design (DOE) was a standard, efficient, statistical approach to research methodology focused on multivariate models and analysis of second order. A standard RSM design called Central Composite Design (CCD) approach for testing the equations of the regression model from the collected data is being used in the current study. The developed regression equations are useful in the analysis of the input parameter interactions affecting the process. The analysis of regression equations draws true and objective conclusions to ensure the experiments are successful. It is also useful to analyze the interactions of the multiple parameters that affect the process.

The RSM technique involves the development of a

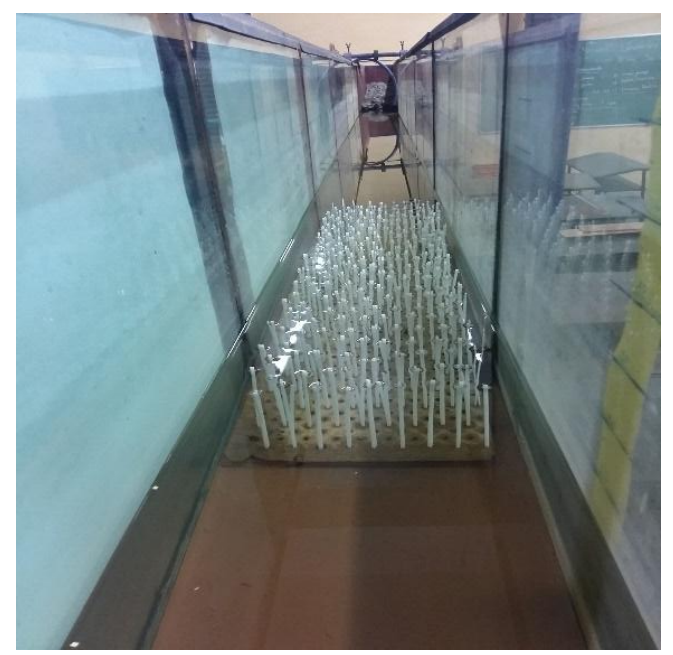

Fig. 2: The plant species imitates the flume under evaluation. 
relationship by polynomial expression of the second-order between the variables $k$. The true link between variables or independent influence factors, $x_{1}, x_{2} \ldots x_{k}$ The following expression in Eqn. 3 can express $x_{k}$ and answer $Y$ (dependent variable):

$$
Y=f\left(x_{1}, x_{2}, \ldots, x_{k}\right)
$$

Where ' $f$ ' is the true response function of an unknown system. The second non-linear polynomial equation to suit the data is given in the form of the following Eqn.4 (Montgomery \& Runger 2014):

$$
Y=\beta_{0}+\sum_{i=1}^{k} \beta_{i} x_{i}+\sum_{i=1}^{k} \sum_{j=1}^{k} \beta_{i j} x_{i} x_{j}+\sum_{i=1}^{k} \beta_{i i} x_{i i}^{2}+\varepsilon \ldots(4)
$$

Where $Y$ is the predicted response (in the present case, wave attenuation efficiency, $E \%$ ); $X_{i}$ and $X_{j}$ are the independent coded variables; $\mathrm{k}$ is the number of factors, $\mathrm{b}_{0}$ is the model's constant term; $\mathrm{b}_{i}, \mathrm{~b}_{i i}, \mathrm{~b}_{i j}$ is the linear, square and interaction effect, and $b$ is the random experimental error respectively. In the present analysis, the Face Centered Central Composite Design (FCCD) approach was used to evaluate and analyze the linear, quadratic, and interaction effects of the variables. Based on the previous analysis four major variables, water depth $(h)$, wave period $(T)$, plant density $(N)$ and bed roughness $(f)$ were selected according to the three levels of each variable with " -1, , " 0 " and " +1 " indicating the low, middle and high factor levels respectively as shown in Table 1. The tests, for example, used steel sheet, fine sand, and coarse pebbles to represent the low $(-1)$, medium (0) and high (+1) bed roughness levels. The FCCD method by nature needs 30 experimental runs and a total of 90 experiments were performed at random with 3 replications to eliminate systematic errors. Statistical software (Minitab (B) software release 17) has been used for statistical analysis of the experimental data and their response surface graph. Regression analysis was performed on the data obtained to determine the effects of the attribution on the expected response of the selected variables, $E \%$. The simulated seagrass meadow for Cymodocea Serrulata, constructed with plastic as a series of modules on board, was fixed firmly together and onto the floor of the flume. Between the flume walls and the meadow, sufficient gap was created to allow free movement of plant mimics to better represent the actual dispersion of the seagrass meadow in shallow water.

\section{RESULTS}

The statistical parameters have been determined using the ANOVA (variance analysis) method. In Eqn.5 the empirical model developed is shown as a coded factor for the E\% prediction:

$$
\begin{aligned}
& Y=\beta_{0}+\beta_{1} h+\beta_{2} T+\beta_{3} N+\beta_{4} f+\beta_{1,2} h T+\beta_{1,3} h N+\beta_{2,3} T N \\
& +\beta_{2,4} T f \ldots+\beta_{1,1}(h)^{2}+\beta_{2,2}(T)^{2}+\beta_{3,3}(N)^{2}+\beta_{4,4}(f)^{2} \quad \ldots(5)
\end{aligned}
$$

Where, $b_{0}$ is an average of responses and $b_{0}, b_{1}, b_{3}$, ..., $b_{44}$ are coefficients for regression (Montgomery et al. 2014), which depend on the respective linear, interaction and quadratic terms of variables. The value for each coefficient was determined using the program. The final empirical model was constructed using the following coefficients as defined in Eqn.6:

$$
\begin{gathered}
E \%=28.42-24.1 h-9.58 T+6.29 h * T+2.43 h * N \\
-3.32 T * N+19.69(h)^{2}+10.24(T)^{2}-25.55(f)^{2} \ldots
\end{gathered}
$$

ANOVA checks the adequacy and statistical importance of the quadratic response model $(E \%)$. The coefficient of multiple determination $\left(R^{2}\right)$ for the quadratic model developed is found to be greater (0.982). The failure to match the $F$-value of the model was found to be 5.05 (not indicated in the table). This large value may occur because of noise. The expected $R^{2}$ value of 0.885 is in good agreement range with the modified $R^{2}$ value of 0.965 . A new series of experiments were carried out under identical experimental conditions to validate the existing regression model. The collected data were compared with the data generated from the regression model and is graphically illustrated in Fig. 3. Every expected value from the established model is well correlated with its new experimental value.

The high $F$ value (28.42) and the corresponding low $p$-value (under 0.0001) indicate that the function and the parameters are statistically significant in the development of a regression model. The effect of $p$-values above 0.05 on the model is statistically negligible. The results show, therefore,

Table 1: Original and coded values of control variables.

\begin{tabular}{|llllll|}
\hline Control variables & Unit & Notation & Coded symbol & \multicolumn{2}{c|}{ The original value of coded levels } \\
\cline { 5 - 7 } & & & & -1 & 0 \\
\hline Water depth & $\mathrm{m}$ & $h$ & $\mathrm{~b}_{1}$ & 0.10 & 0.125 \\
Wave period & $\mathrm{s}$ & $T$ & $\mathrm{~b}_{2}$ & 1.0 & 2.0 \\
Plant density & stems/sqm & $N$ & $\mathrm{~b}_{3}$ & 543 & 1353 \\
Bed roughness factor & - & $f$ & $\mathrm{~b}_{4}$ & 0.010 & 0.017 \\
\hline
\end{tabular}




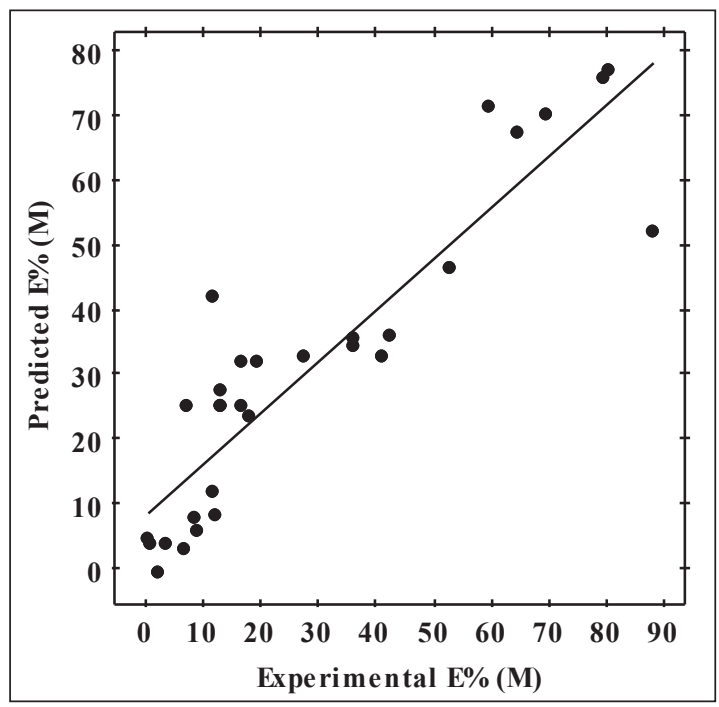

Fig. 3: Comparison between predicted and experimental E\%.

that all non-linear terms $h$ and $\mathrm{T}$ are relevant; quadratic terms $(T)^{2},(h)^{2}$ and $(f)^{2}$ together with the interaction terms $(h)^{*}(T)$, $(h)^{*}(N)$ and $(T) *(N)$ are significant in response, and $E \%$. The quadratic $(N)^{2}$ terms and the interaction $(h)^{*}(f) ;(T)^{*}(f)$ and $(N) *(f)$ terms have a marginal impact within a design range defined.

Impact of parameters: The results from the probability value $F$-statistics ( $p$ less than 0.05 ) suggested that the Eqn. 6 models could establish a strong correlation between the input and output variables. Parametric variables $h, T, N$, and $f$ are important for the attenuation of waves caused by vegetation. The graphical representation of the statistically-dependent interaction effects of the two-way factors with their respective regression model (E\%) is shown in Fig. 4.

Model parameter interaction results: The interaction effects of all statistically relevant $E \%$ variable on the vegetation meadow are graphically represented in the following sections. The images showing the effect of two-way interaction between the four-wave attenuation parameters are $h$ - $T$ (Fig. 4 (A) and Fig. 5) and $h-N$ (Fig. 4 (B) and Fig. 6) relationship; $T-N$ (Fig. 4 (C) and Fig. 7) inverse relation.

Interaction effect of $\boldsymbol{h}$ and $\boldsymbol{T}$ : Fig. 5(A) and (B) show the $E \%$ interaction effect of $h$ and $T$ on the vegetation region. In the case of plant stem density $N$ (1353 stems/sqm) and friction factor $f(0.0175), E \%$ is plotted here. At lower $h$ $(0.10 \mathrm{~m})$ and $T(1.0 \mathrm{~s}), E \%$ is the highest $(98.32 \%)$ and the

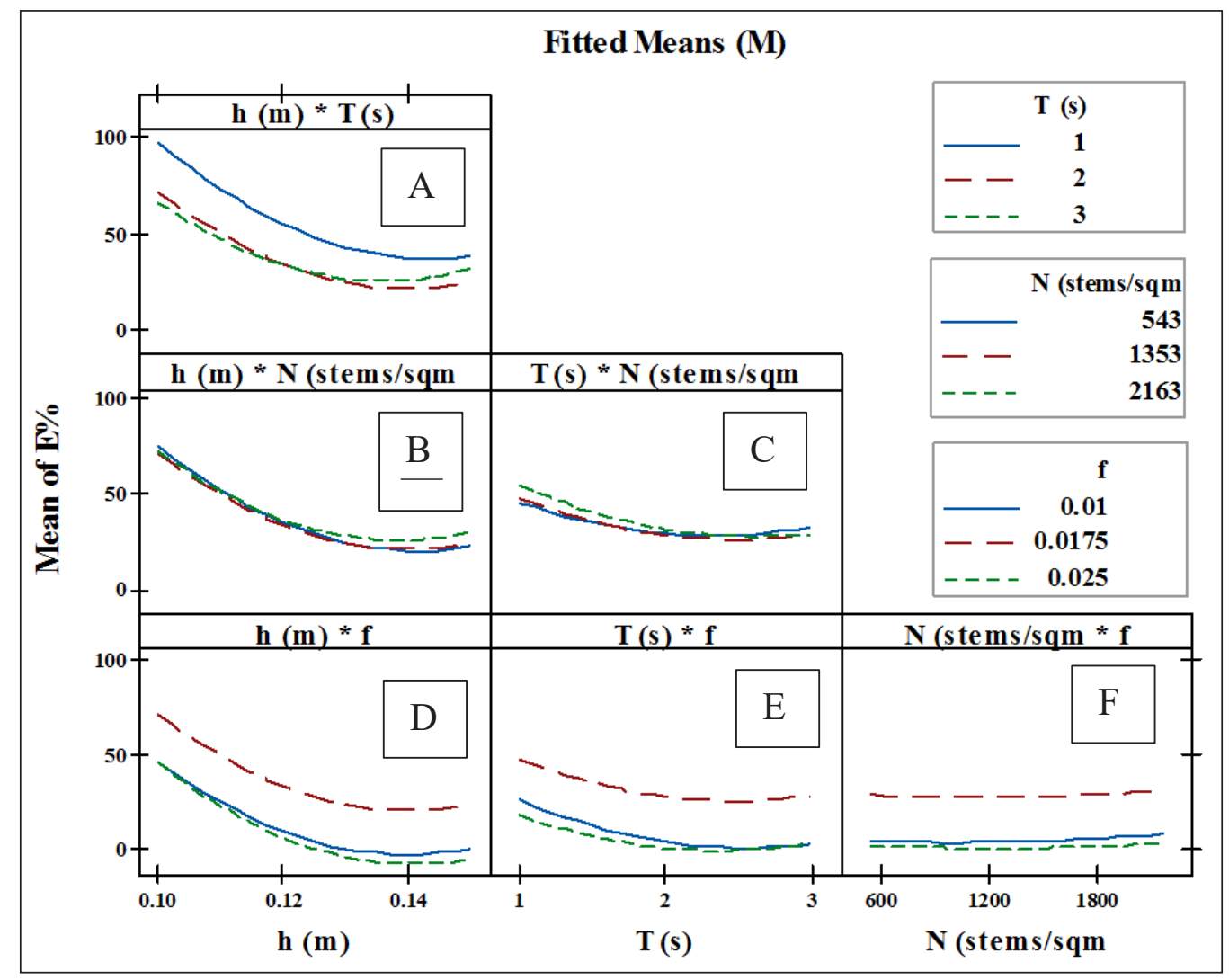

Fig. 4: Two-way interaction effect. 
improvement resulted in a decrease in energy loss as the waves passed through the vegetation zone and decreased to as low as $(37.53 \%)$. With the wave period, the $E \%$ rises to the small $T$-values point and gradually decreases to the large $T$-values as it travels through the vegetation field. It may be attributed to wider changes in the coefficients of empiric wave decay over short peak wave cycles and almost converging over longer $T$. Also, theoretical coefficients of wave decay are found to be almost independent during variations from peak periods under dips. This is consistent with the study by Huang et al. (2011) that vegetation density and incident wave height are the two variables that often affect wave propagation coefficients.

Interaction effect of $\boldsymbol{h}$ and $\boldsymbol{N}$ : The regression model developed by Eqn. 6 claimed that the relationship between $h$ and $N$ had a positive effect on $\mathrm{E} \%$, while $N$ had a positive effect individually. Fig. 6(A) and (B) display the interaction effect at constant wave period, $2 \mathrm{~s}$ and friction factor, 0.0175 as a function of $\mathrm{h}$ and $N$ at $E \%$. The increase from $543 \mathrm{stems} / \mathrm{sqm}$ to $2163 \mathrm{stems} / \mathrm{sqm}$ in plant density $N$ means that the $E \%$ is around $73.16 \%$. Such findings are consistent with the published results (Bouma et al. 2005), although the published results are not compatible with the effect of $N$ on $E \%$. As far as the relationship of plant density to wave attenuation is concerned, literature was also contradictory as some studies found that there was no impact from higher plant density (Fonseca \& Cahalan 1992) and some other results showed an increase in wave dissipation (Bouma et al. 2005). Nevertheless, the fact that plant morphology (Koch et al. 2006) and mechanical plant morphology such as shoot stiffness (Bouma et al. 2005) have a closer relationship to wave dissipation has been generally acknowledged.
Interaction effect of $\boldsymbol{T}$ and $N$ : There is also a statistically important interaction effect between $T$ and $N$ on wave attenuation. Fig. 7(A) and (B) illustrate the interaction effects of $T$ and $N$ on the vegetation $E \%$ in the meadow. Indeed, since the cumulative interaction effect is directly proportional to $E \%$, an increase of $T$ at minimum $N$ from $1 \mathrm{~s}$ to $3 \mathrm{~s}$ results in an increase of $E \%$. The surface plot Fig. 7(B) also shows that the shorter wave duration $(1 \mathrm{~s})$ results in a higher percentage of wave energy reduction (55\%) for maximum plant intensity. At the longest wave period ( $3 \mathrm{~s}$ ), however, the highest $N$ results in the lowest percentage of wave energy reduction $(29.16 \%)$. On the contrary, in the shorter wave duration (1 s), the lower $N$ results in a higher percentage of wave energy reduction (46\%). Möller et al. (1999) stated that, in all wave cycles, salt marshes reduced wave energy to the same degree as flat sand flows at the bottom. However, other studies (Lowe et al. 2007 ) indicated that attenuation of the vegetationbased wave is primarily dependent on high-frequency wave time. Stratigaki et al. (2011) observed a decrease of 35\% in meadow wave height due to a drop in wave frequency. From this analysis, the inverse non-linear effect of the wave cycle on energy variability in the vegetation meadow (Fig. 7A and $\mathrm{B})$ is in good agreement with the published findings.

\section{CONCLUSIONS}

The results indicated that all the parameters considered, such as water depth $h$, wave period $T$, plant density $N$ and bed roughness factor $f$, have a statistically significant effect on wave energy attenuation under specified conditions. The results also verified that both $h$ and $T$ have independently negative effects and hence positive nonlinear effects, where-

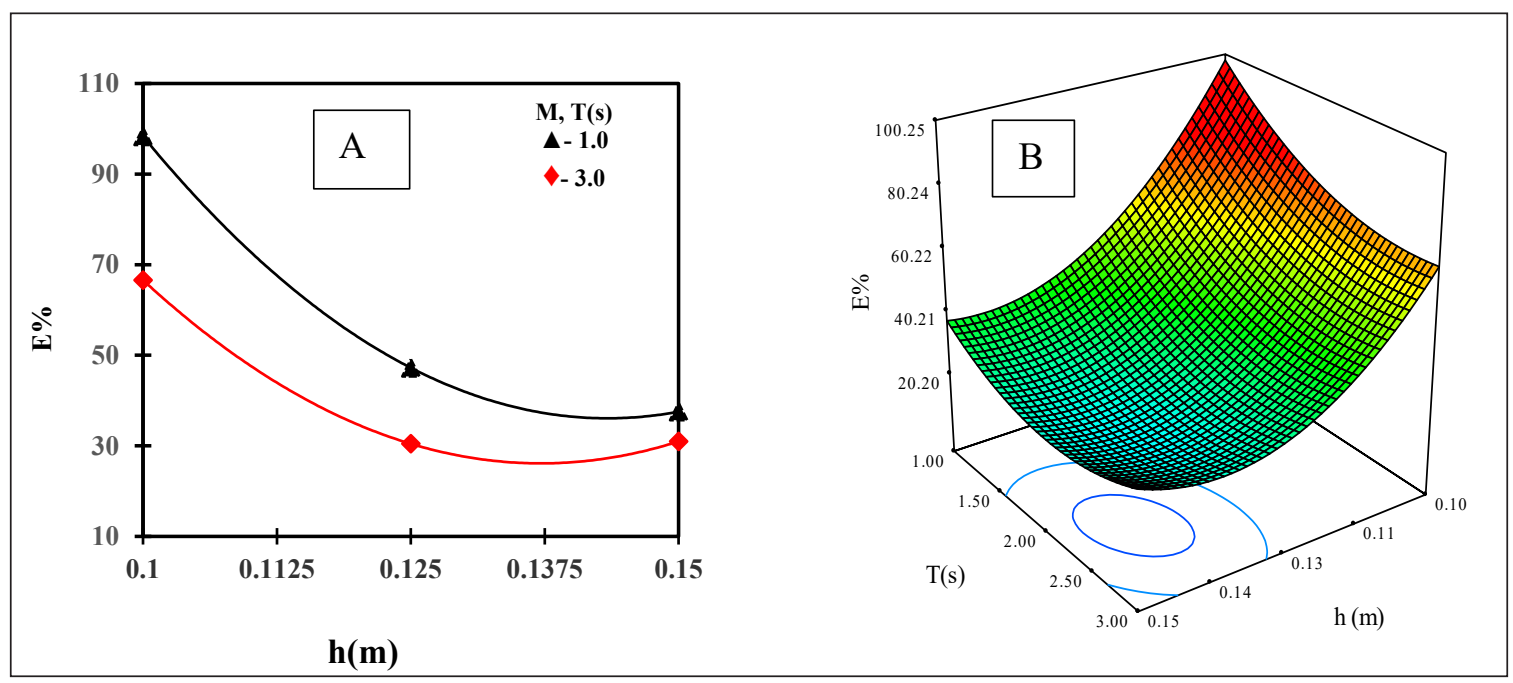

Fig. 5: Interaction effect of $h$ and $T$ on $E \%$, two-way interaction effect (A), surface plot (B). 


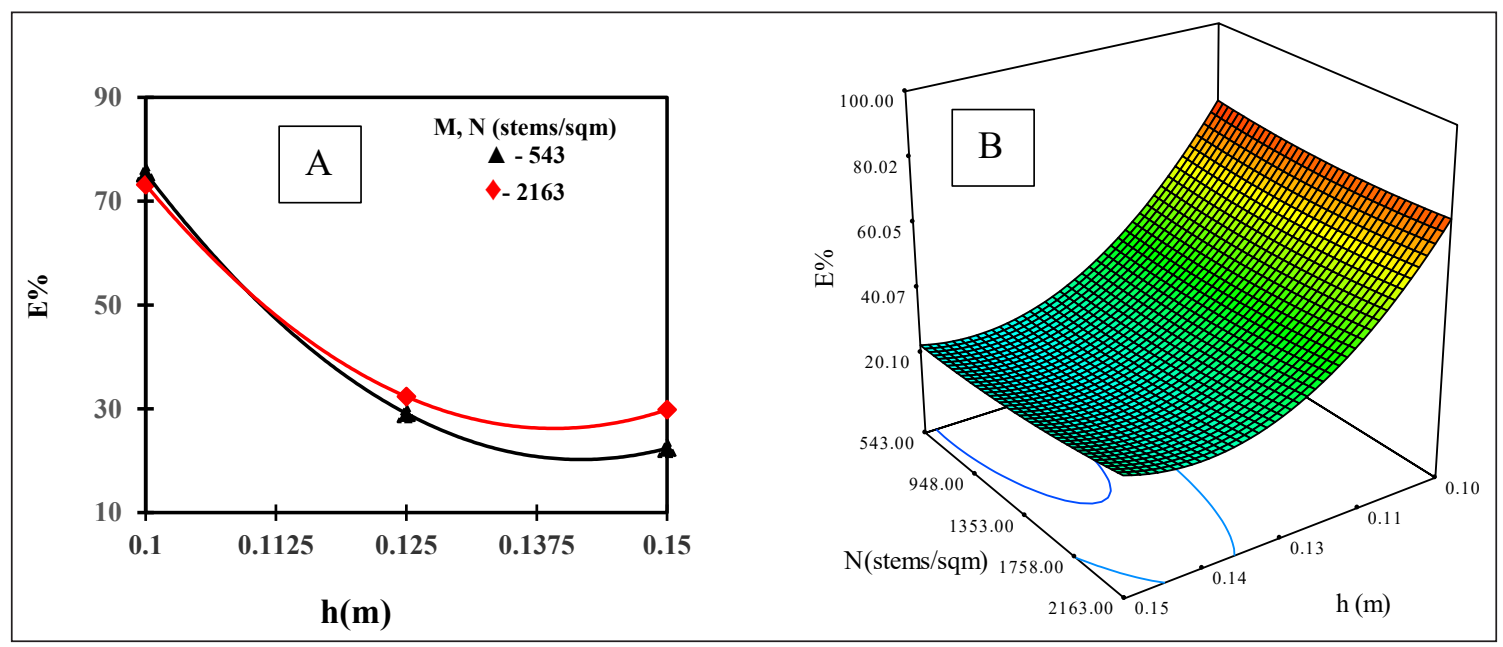

Fig. 6: Interaction effect of $h$ and $N$ on $E \%$, two-way interaction effect (A), surface plot (B).

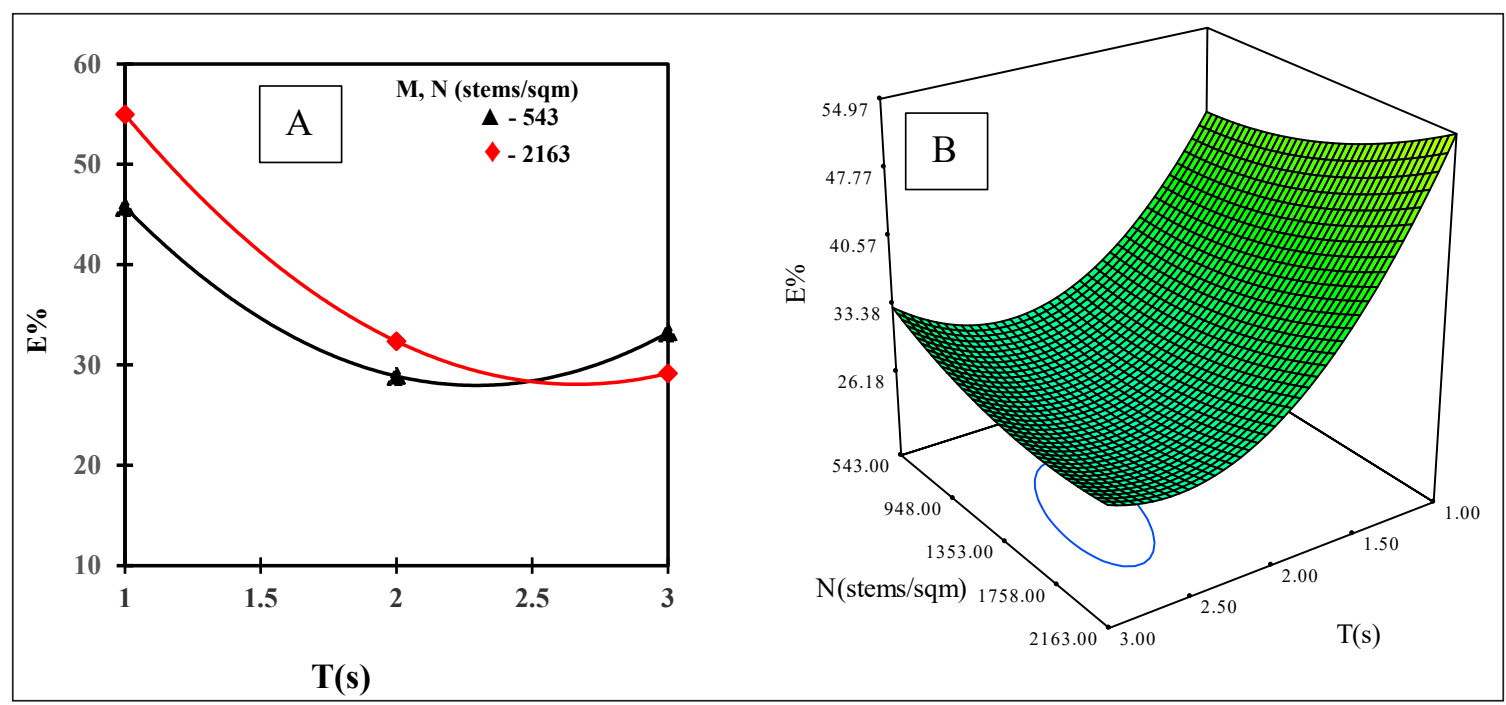

Fig. 7: Interaction effect of $T$ and $N$ on $E \%$, two-way interaction effect (A), surface plot (B).

as $T$ and $N$ have a negative interaction effect with $f$ on $E \%$. Water depth contributes most to wave attenuation because it has statistically important bidirectional interactions with two of the other two parameters ( $N$ and $T$ ). The RSM technique was found to be extremely effective in predicting the reduction of wave energy by monotypic seagrass meadow as the results of the variance analysis (ANOVA) showed good agreement when comparing the experimental results with the model predictions at a high determination coefficient $\left(R^{2}\right)$ of 0.965 (with $p$-value $<0.05$ ).

\section{REFERENCES}

Bouma, T.J., De Vries, M.B., Low, E., Peralta, G., Tánczos, I.C., Van De Koppel, J. and Herman P.M.J. 2005. Trade-offs related to ecosystem engineering: A case study on stiffness of emerging macrophytes. Ecology, 86 (8): 2187-2199 DOI: 10.1890/04-1588

Feagin, R.A., Furman, M., Salgado, K., Martinez, M.L., Innocenti, R.A., Eubanks, K., Figlus, J., Huff, T.P., Sigren, J. and Silva, R. 2019. Estuarine, coastal and shelf science the role of beach and sand dune vegetation in mediating wave run up erosion. Estuarine, Coastal and Shelf Science, 219 (September 2018): 97-106 DOI: 10.1016/j. ecss.2019.01.018

Fonseca, M.S. and Cahalan, J.A. 1992. A preliminary evaluation of wave attenuation by four species of seagrass. Estuarine, Coastal and Shelf Science, 35(6): 565-576 DOI: 10.1016/S0272-7714(05)80039-3.

Guannel, G., Ruggiero, P., Faries, J., Arkema, K., Pinsky, M., Gelfenbaum, G., Guerry, A. and Kim, C.K. 2015. Integrated modeling framework to quantify the coastal protection services supplied by vegetation. Journal of Geophysical Research: Oceans, 120(1) DOI: 10.1002/2014JC009821.

Huang, Z., Yao, Y., Sim, S.Y. and Yao, Y. 2011. Interaction of solitary waves with emergent, rigid vegetation. Ocean Engineering, 38 (10): 10801088 DOI: $10.1016 /$ j.oceaneng.2011.03.003. 
Koch, E.W., Sanford, L.P., Chen, S.N., Shafer, D.J. and Smith, J.M. 2006. Waves in seagrass systems: review and technical recommendations (No. ERDC-TR-06-15). (November)

Kuo, J., den Hartog, C. 2006. Taxonomy and biogeography of seagrasses. Seagrasses: Biology, Ecology, and Conservation: 1-23, Availableat: file://localhost/Users/timsherman/Documents/Papers/2006/den Hartog/ Taxonomy and Biogeography of Seagrasses 2006 den Hartog.pdf

Larkum, A.W.D., Orth, R.J. and Duarte, C.M. 2006. Seagrasses: biology, ecology and conservation. Seagrasses: Biology, Ecology and Conservation, (May): 1-691 DOI: 10.1007/978-1-4020-2983-7

Lowe, R.J., Falter, J.L., Koseff, J.R., Monismith, S.G. and Atkinson, M.J. 2007. Spectral wave flow attenuation within submerged canopies: Implications for wave energy dissipation. Journal of Geophysical Research: Oceans, 112(5): 1-14 DOI: 10.1029/2006JC003605

Luhar, M. and Nepf, H.M. 2016. Wave-induced dynamics of flexible blades. Journal of Fluids and Structures, 61: 20-41 DOI: 10.1016/j. jfluidstructs.2015.11.007

Manca, E., Cáceres, I., Alsina, J.M., Stratigaki, V., Townend, I. and Amos, C.L. 2012. Wave energy and wave-induced flow reduction by full-scale model Posidonia oceanica seagrass. Continental Shelf Research, 50-51: 100-116 DOI: 10.1016/j.csr.2012.10.008.

Möller, I., Spencer, T., French, J.R., Leggett, D.J. and Dixon, M. 1999. Wave transformation over saltmarshes: a field and numerical modelling study from North Norfolk, England. Estuarine, Coastal and Shelf Science, 49: 411-426. DOI: 10.1006/ecss.1999.0509

Montgomery, D.C. and Runger, G.C. 2014. Applied Statistics and Probability for Engineers. Eur. J. Eng. Educ., 19(3): 383.

Specht, A., Gordon, I.J., Groves, R.H., Lambers, H. and Phinn, S.R. 2015. Catalysing transdisciplinary synthesis in ecosystem science and management. Science of the Total Environment, 534: 1-3. DOI: 10.1016/j.scitotenv.2015.06.044

Stratigaki, V., Manca, E., Prinos, P., Losada, I.J., Lara, J.L., Sclavo, M., Amos, C.L., Cáceres, I. and Sánchez-Arcilla, A. 2011. Large-scale experiments on wave propagation over Posidonia oceanica. Journal of Hydraulic Research, 49 (SUPPL.1): 31-43. DOI: 10.1080/00221686.2011.583388

Vuik, V., Suh Heo, H.Y., Zhu, Z., Borsje, B.W. and Jonkman, S.N. 2018. Stem breakage of salt marsh vegetation under wave forcing: A field and model study. Estuarine, Coastal and Shelf Science, 200: 41-58 DOI: 10.1016/j.ecss.2017.09.028

Xu, S., Liu, Y., Wang, X. and Zhang, G. 2017. Scale effect on spatial patterns of ecosystem services and associations among them in semiarid area: A case study in Ningxia Hui Autonomous Region, China. Science of the Total Environment, 598: 297-306 DOI: 10.1016/j. scitotenv.2017.04.009 